\title{
Cathodoluminescence and photoinduced current spectroscopy studies of defects in $\mathrm{Cd}_{0.8} \mathrm{Zn}_{0.2} \mathrm{Te}$
}

\author{
A. Castaldini, A. Cavallini, B. Fraboni, and L. Polenta \\ Istituto Nazionale di Fisica della Materia, Departement of Physics, University of Bologna, via Irnerio 46, 40126 Bologna, Italy \\ P. Fernandez and J. Piqueras \\ Departamento de Física de Materiales, Universidad Complutense de Madrid, E-28040 Madrid, Spain
}

(Received 24 October 1995; revised manuscript received 24 April 1996)

\begin{abstract}
Deep levels in $\mathrm{Cd}_{1-x} \mathrm{Zn}_{x}$ Te have not yet been fully characterized and understood, even though this material is very promising for medical and optoelectronic applications. We have investigated $p$-type semi-insulating $\mathrm{Cd}_{0.8} \mathrm{Zn}_{0.2}$ Te with cathodoluminescence (CL) and photoinduced current transient spectroscopy (PICTS) methods. PICTS analyses allow detection of deep levels which are not revealed by other current spectroscopy techniques generally used, as they permit scanning of a wider region of the energy gap. Five levels have been detected $(0.16,0.25,0.57,0.78$, and $1.1 \mathrm{eV})$ and, by combining the results obtained with the above-mentioned CL techniques, we were able to advance hypotheses on the character (donor or acceptor) and origin of some of these levels. The key role played by the $0.78-\mathrm{eV}$ level in controlling the carrier transport properties has also been confirmed. [S0163-1829(96)00535-8]
\end{abstract}

Zinc cadmium telluride $\left(\mathrm{Cd}_{1-x} \mathrm{Zn}_{x} \mathrm{Te}\right)$ has become of interest in recent years due to its special properties. Its applications cover a wide range from medical physics, as a detector for $\mathrm{x}$ rays and $\gamma$ rays, to optoelectronics, as a substrate material and a superlattice component. One of its major features is the high resistivity of as-grown material and the consequent low leakage current. Moreover, its direct band gap can be continuously tuned from the CdTe gap $(1.45 \mathrm{eV})$ to the $\mathrm{ZnTe}$ one $(2.3 \mathrm{eV})$ by varying the $\mathrm{Zn}$ concentration. ${ }^{1} \mathrm{In}$ addition, the lattice parameters of $\mathrm{Cd}_{1-x} \mathrm{Zn}_{x} \mathrm{Te}$ can be matched to those of $\mathrm{Hg}_{1-y} \mathrm{Cd}_{y} \mathrm{Te}$, thus inhibiting the formation of misfit dislocations during epitaxial growth. This is particularly true for $x=0.2$. As the semi-insulating character of $\mathrm{Cd}_{1-x} \mathrm{Zn}_{x} \mathrm{Te}$ is not obtained by adding impurities to the as-grown material, these do not contribute to the deep-level spectrum. Nonetheless, knowledge of the existing deep levels associated with the growth process is crucial to conveniently tailoring the optical and electrical properties of the material. Only a few results on investigations of deep levels in $\mathrm{Cd}_{1-x} \mathrm{Zn}_{x}$ Te have appeared so far in the literature, and a better understanding of their properties and nature is needed Capacitance junction spectroscopy cannot be used to investigate semi-insulating materials, which require dedicated spectroscopies such as photoinduced current transient spectroscopy (PICTS). ${ }^{2,3}$ The PICTS method has the special feature of detecting traps which may lay quite deep in the forbidden gap, a characteristic which other commonly used techniques (e.g., thermally stimulated current) do not possess. In addition, luminescence techniques are suitable to investigate the electronic properties of defects in this ternary compound.

For a deeper understanding of the origin and nature of defects in $\mathrm{Cd}_{1-x} \mathrm{Zn}_{x} \mathrm{Te}$, this paper reports results obtained with both cathodoluminescence (CL) and PICTS measurements. We have investigated a 3 -mm-thick $\mathrm{Cd}_{0.8} \mathrm{Zn}_{0.2}$ Te wafer grown by the high-pressure vertical Bridgman method provided by the Aurora Tech. Corp., San Diego, California. The material is semi-insulating, with a resistivity $1.5 \times 10^{11}$
$\Omega \mathrm{cm}$, slightly $p$ type. PICTS measurements have been carried out in two sample configurations: planar (i.e., with two Ohmic contacts) and Schottky (i.e., with an Al Schottky barrier on top and a backside Ohmic contact). The Ohmic contacts have been prepared with an InHg alloy. We employed incident excitation light of two different wavelengths, namely, $\lambda=670$ and $880 \mathrm{~nm}$, corresponding, respectively, to 1.85 (above band gap) and $1.41 \mathrm{eV}$ (below band gap), to vary the carrier excitation conditions. Cathodoluminescence measurements have been performed in a Hitachi S-2500 scanning electron microscope at $T=80 \mathrm{~K}$ with an accelerating voltage of $25 \mathrm{kV}$. Emission has been measured with a germanium detector. Spectra have been recorded under different focusing conditions of the electron beam on the sample, to account for radiative centers with low concentration. Usually by defocusing, the intensity of the deep-level bands increases.

The electrical characterization of the deep levels in $\mathrm{Cd}_{0.8} \mathrm{Zn}_{0.2} \mathrm{Te}$ revealed the existence of five major traps. PICTS analyses in the planar and barrier configurations produced the same results, the barrier spectra being better resolved. ${ }^{4}$ The spectrum for exciting wavelength $\lambda=880 \mathrm{~nm}$ is reported in Fig. 1 for the Schottky configuration. Figure 2 shows the Arrhenius plot of the levels labelled $A, B, C, D$, and $E$ in Fig. 1, obtained with data from both wavelength spectra. Some differences are induced in the PICTS spectra by the different exciting wavelength. Figure 3 reports a comparison of a $\lambda=670-\mathrm{nm}$ and a $\lambda=880-\mathrm{nm}$ spectrum obtained in a Schottky configuration with the same experimental conditions. It is worth noting that, even though the power of the source with $\lambda=670 \mathrm{~nm}$ is lower than the one with $\lambda=880$ $\mathrm{nm}$, peak $C$ is better resolved in the former spectrum. This could be attributed to the different transitions induced by an above-band-gap light $(\lambda=670 \mathrm{~nm})$ and by a below-band-gap one $(\lambda=880 \mathrm{~nm})$. The photocurrent values at low temperature are quite low for both exciting wavelengths, and the shallowest level $A$ results are quite noisy in most spectra. 


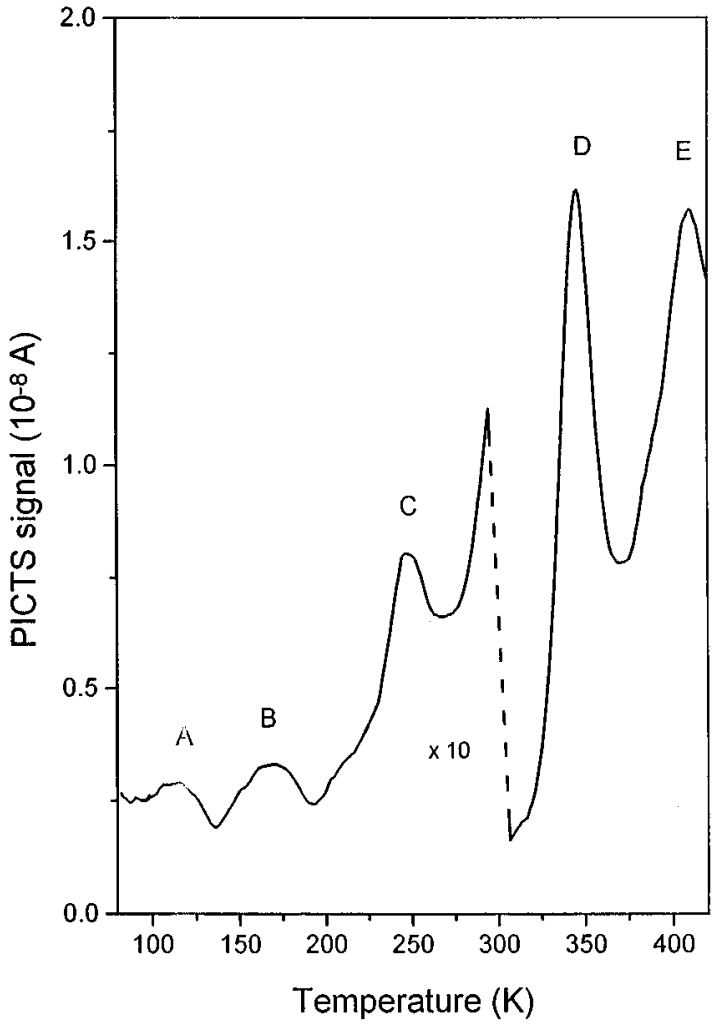

FIG. 1. PICTS spectrum in a planar configuration with $\lambda=880$ $\mathrm{nm}$ and $e_{n}=256.41 \mathrm{~s}^{-1}$.

The optical characterization of the same samples was carried out with cathodoluminescence (CL) measurements. Figure 4 shows CL spectra at $T=80 \mathrm{~K}$. Three bands can be resolved, at $1.45,1.05$, and $0.77 \mathrm{eV}$. Focusing causes the enhancement of the $1.05-\mathrm{eV}$ band, while in the defocused spectrum the 1.45 - and $0.75-\mathrm{eV}$ bands are more clearly observed. The broad and nonsymmetric $1.45-\mathrm{eV}$ band has been determined by deconvolution to be composed of two subbands peaked at 1.50 and $1.40 \mathrm{eV}$, respectively.

In order to discuss our experimental findings, one needs to take into account that in $\mathrm{Cd}_{1-x} \mathrm{Zn}_{x} \mathrm{Te} \mathrm{Zn}$ is supposed to reside on $\mathrm{Cd}$ sites, thus decreasing the $\mathrm{V}_{\mathrm{Cd}}^{+}$concentration

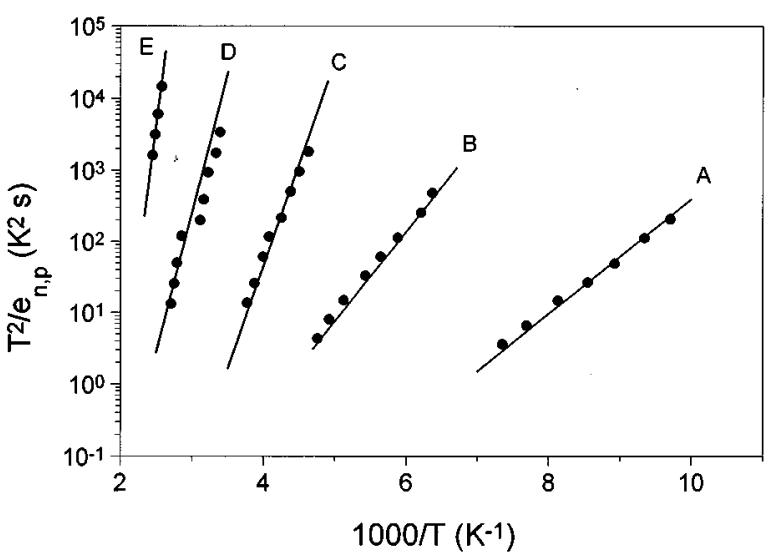

FIG. 2. Arrhenius plot of the levels detected. The symbols refer to results obtained with $\lambda=880$ and $670 \mathrm{~nm}$. Solid lines represent the fitting of experimental data.

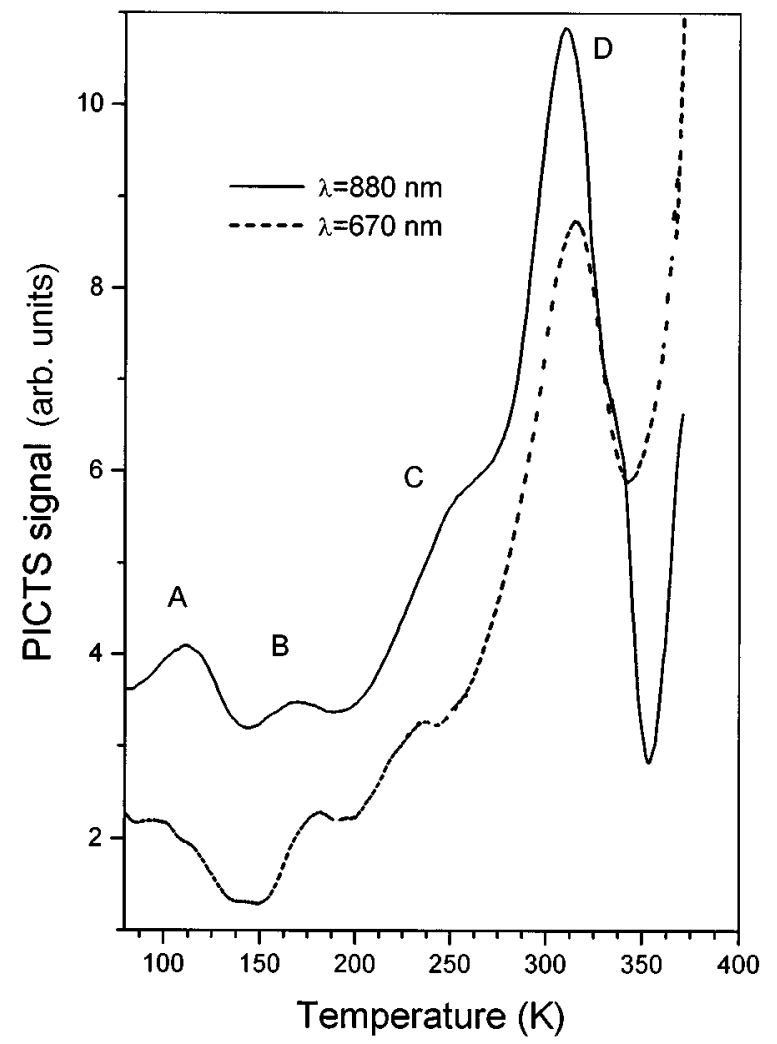

FIG. 3. PICTS spectra in a Schottky configuration for $\lambda=670$ $\mathrm{nm}$ (dotted line) and $\lambda=880 \mathrm{~nm}$ (continuous line) with $e_{n}=256.41 \mathrm{~s}^{-1}$.

and, hence, increasing the material resistivity., ${ }^{5,6}$ Moreover, the band gap varies with $\mathrm{Zn}$ concentration from $1.45 \mathrm{eV}$ in $\mathrm{CdTe}$ to $2.3 \mathrm{eV}$ in $\mathrm{ZnTe}$. For the ternary compound $\mathrm{Cd}_{0.8} \mathrm{Zn}_{0.2} \mathrm{Te}$ here investigated, the band gap is $1.65 \mathrm{eV}$ at room temperature. The band-gap variation as a function of temperature can be calculated from the Varshni equation $E_{g}(T)=E_{0}-\left[\alpha T^{2} /(\beta+T)\right],{ }^{7}$ with $\alpha=6.49 \times 10^{-4} \mathrm{eV} / \mathrm{K}$ and $\beta=265 \mathrm{~K}$, corresponding to the $\mathrm{Zn}$ concentration of the investigated material. ${ }^{8}$ The valence band does not shift much with increasing $\mathrm{Zn}$ concentration, while the conduction band

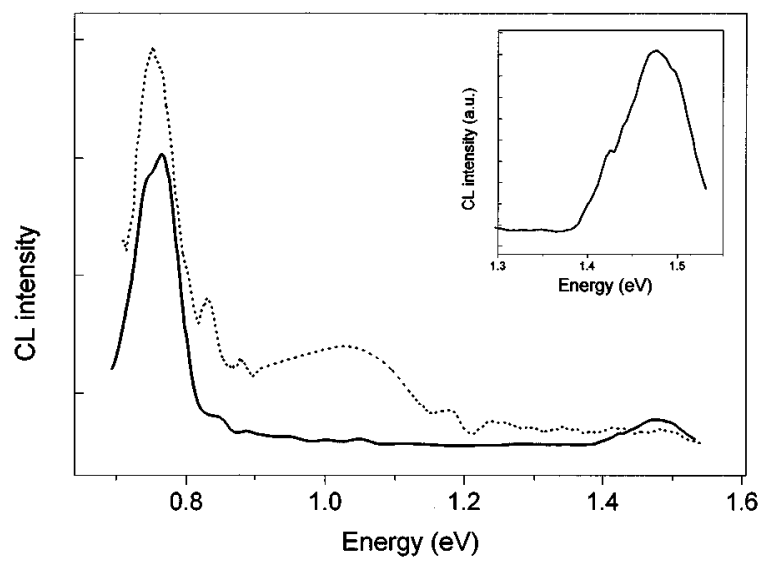

FIG. 4. CL spectra recorded under focused (dotted line) and defocused (solid line) conditions at $T=80 \mathrm{~K}$. The inset shows a detail of the $1.45-\mathrm{eV}$ band under defocused conditions. 
TABLE I. Activation energies and capture cross section of the levels found by CL and PICTS measurements. A tentative defect identification is also reported.

\begin{tabular}{lcccccc}
\hline \hline Level & & $A$ & $B$ & $C$ & $D$ & $E$ \\
\hline CL & $E_{a}(\mathrm{eV})$ & 1.5 & 1.4 & & 0.77 & 1.05 \\
PICTS & $E_{a}(\mathrm{eV})$ & 0.16 & 0.25 & 0.57 & 0.78 & 1.1 \\
& $\sigma\left(\mathrm{cm}^{2}\right)$ & $3 \times 10^{-16}$ & $2.5 \times 10^{-16}$ & $3 \times 10^{-12}$ & $2.5 \times 10^{-12}$ & $1 \times 10^{-10}$ \\
Tentative & & $A$ center & Zn related & $V_{\text {Zn }}$ related & $V_{\mathrm{Cd}}^{--}$ & $V_{\mathrm{Te}}$ \\
identification & & $\mathrm{Cu}$ or Ag & & & \\
\hline
\end{tabular}

rises markedly. The valence band is related to the $\mathrm{Cd}$ sublattice (and related defects), while the conduction band is related to the Te sublattice. ${ }^{9}$ As the PICTS method does not determine the trap sign, i.e., if it is a majority or minority carrier trap, it is hard to state if the measured activation energy $E_{a}$ has to be calculated from the valence or the conduction band. To properly identify the level, one has to relate the PICTS results to other trap characterization methods. This is why we have correlated CL and PICTS results. $E_{a}$ and the carrier capture cross section $\sigma$ are reported in Table I, together with the possible attribution of the level.

Level A: In the PICTS spectra a level at $0.16 \mathrm{eV}$ is detected. A similar trap has been found in the literature with PICTS measurements of $\mathrm{Cd}_{0.9} \mathrm{Zn}_{0.1}$ Te. ${ }^{10}$ Other thermally stimulated current (TSC) and deep-level transient spectroscopy (DLTS) measurements provide indication of a $0.15-\mathrm{eV}$ level in CdTe. ${ }^{1-14}$ Luminescence measurements on $\mathrm{Cd}_{1-x} \mathrm{Zn}_{x}$ Te reported in the literature identify an emission band located at approximately $1.5 \mathrm{eV} \cdot{ }^{1,8,12,15}$ Such a band has also been found in our CL measurements, and, as the band gap is approximately $1.65 \mathrm{eV}$ we can conclude that the 0.15 or 0.16-eV PICTS level and the 1.5-eV CL band are generated by the same defect. Its structure has been proposed to be a complex with a $V_{\mathrm{Cd}}$ and a donor in the form $V_{\mathrm{Cd}^{-}}^{-}$Don $_{\mathrm{Te}}$, usually called center $A .^{12,14-16}$ In our undoped material donors could be present as unintentional impurities, as previously observed in other undoped CdTe samples. ${ }^{20}$ A contribution to the emission band could also be provided by $\mathrm{Cu}$ and $\mathrm{Ag}$, which are dominant residual impurities. ${ }^{15}$ The level behaves as an acceptor, and thus is located at $E_{v}+0.15 \mathrm{eV}$. It has been observed that the level associated with center $A$ remains constant at $E_{v}+0.15 \mathrm{eV}$ from CdTe $(x=0)$ (Refs. 15 and 17) up to ZnTe $(x=1)$ while its associated luminescence energy increases as the band gap from CdTe $(1.45 \mathrm{eV})$ to $\mathrm{ZnTe}(2.3 \mathrm{eV}){ }^{9}{ }^{9}$ The fact that level $A$ follows the valenceband behavior confirms its attribution to a $\mathrm{Cd}$ sublattice defect. $^{6}$

Level B: The level determined by PICTS measurements to be located at $0.25 \mathrm{eV}$ could be related to the level at $0.31 \mathrm{eV}$ found in PICTS investigations of $\mathrm{Cd}_{0.9} \mathrm{Zn}_{0.1}$ Te and attributed to $\mathrm{Zn},{ }^{10}$ or to the one at $0.27 \mathrm{eV}$ found in $\mathrm{Cd}_{1-x} \mathrm{Zn}_{x} \mathrm{Te}: \mathrm{In}$ and again assigned to a $\mathrm{Zn}$-related defect. ${ }^{6}$ The $\mathrm{Zn}$ attribution is supported by the absence of such a level in PICTS analyses of CdTe doped and undoped samples. ${ }^{17}$ In our CL measurements the band that could be associated with this level is one of the two components of the $1.45-\mathrm{eV}$ centered broadband, namely, the one at $1.40 \mathrm{eV}$. However, we do not have sufficient information to identify the defect luminescence properties and, therefore, whether its activation energy has to be measured from the valence or conduction band. Conductance measurements reported in the literature suggest that its activation energy is measured from the valence band, $E_{a}=E_{V}+0.27 \mathrm{eV}^{6,18}$

Level $C$ : By comparing the $\lambda=880$ - and $670-\mathrm{nm}$ spectra, it is worth noting that peak $C$ is more clearly resolved in the former one. Therefore the data reported in the Arrhenius plot (Fig. 2) refer to the $\lambda=670-\mathrm{nm}$ results which are more reliable. The 0.57-eV PICTS level cannot be related to any of the major traps found in $\mathrm{CdTe},{ }^{17}$ and appears to be present only in $\mathrm{Cd}_{1-x} \mathrm{Zn}_{x} \mathrm{Te}$. A similar trap has, in fact, been found in PICTS measurements of $\mathrm{Cd}_{0.9} \mathrm{Zn}_{0.1} \mathrm{Te}$ at $0.54 \mathrm{eV}$, with $\sigma=1 \times 10^{-10} \mathrm{~cm}^{-2},{ }^{10}$ but the Arrhenius plots of these two traps do not have much in common. The CL analysis does not straightforwardly suggest the existence of a band associated with this energy. However, it has been suggested ${ }^{18}$ that the defect located at $0.55-0.65 \mathrm{eV}$ has an acceptor character and is related to a $\mathrm{Zn}$ vacancy.

Level D: The 0.78-eV peak was the most prominent in our PICTs and CL measurements of $\mathrm{Cd}_{0.8} \mathrm{Zn}_{0.2}$ Te samples. Bulk current measurements as a function of temperature confirm that the transport process is controlled by this trap for both exciting wavelengths, ${ }^{19}$ as shown in Fig. 5. It has been reported in the literature as one of the most common levels in II-VI binary and ternary compounds. It has been investigated both with electrical ${ }^{10,13,14,17}$ and optical characterization techniques, ${ }^{12,15,20-22}$ and has been associated with a deep acceptor $V_{\mathrm{Cd}}^{-}$, which plays a crucial role in the compensation mechanism and in the pinning of the Fermi level. More detailed investigations tend to attribute the level to a $\mathrm{V}_{\mathrm{Cd}}^{-}$associated with an impurity, ${ }^{20,26}$ and have provided indication for its behavior as a recombination center with $e_{p} \sim 5 e_{n} \cdot{ }^{26}$ This explains why it is detectable with DLTS in $n$ - and

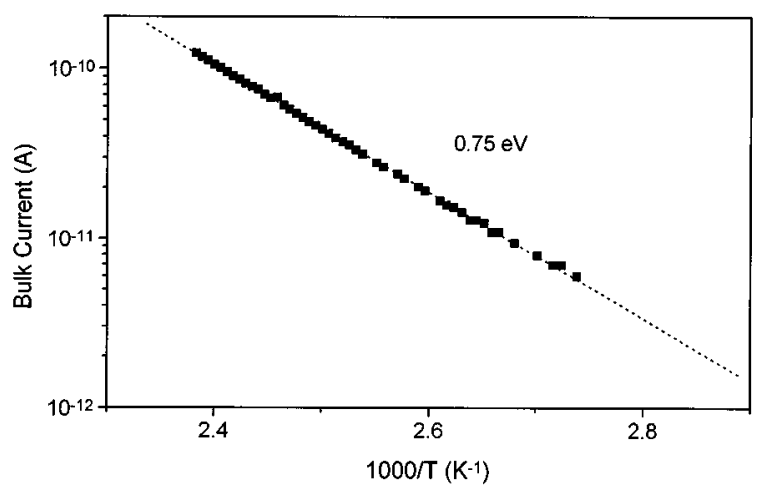

FIG. 5. Bulk current vs temperature measured for $\lambda=880 \mathrm{~nm}$. The slope of the dotted line (fitting curve) is $0.75 \mathrm{eV}$. 
$p$-type semiconducting materials. ${ }^{17,26}$ As we are investigating optically induced transitions in $p$-type material, the majority-carrier optical cross section is likely to control the process and, therefore, we can locate the level at $E_{a}=E_{V}+0.78 \mathrm{eV}$.

Level E: The last level to be discussed is the one detected in PICTS measurements at $1.1 \mathrm{eV}$. CL spectra show a band at $1.05 \mathrm{eV}$, more evident in the focused spectrum, which has been found in the past in CdTe and $\mathrm{Cd}_{1-x} \mathrm{Zn}_{x} \mathrm{Te}$ and widely attributed to an intrinsic defect $V_{\mathrm{Te}} \cdot 1,9,13,15$ As this level is related to a donor trap, its activation energy has to be measured from the conduction band, $E_{a}=E_{c}-1.1 \mathrm{eV} .{ }^{16} \mathrm{In}$ PICTS/DLTS measurements the peak associated with this level is hard to detect because, at the high temperature corresponding to the maximum emission of this trap, the bulk current increases strongly. However, by conveniently adjusting the measuring conditions, we have clearly revealed its presence (Fig. 1).
In conclusion, we have investigated the levels induced by native defects in $\mathrm{Cd}_{0.8} \mathrm{Zn}_{0.2}$ Te by $\mathrm{CL}$ and PICTS methods. By combining the results obtained with these techniques we were able to identify the nature of some of the defects detected. Five major traps have been revealed in the ternary compound studied, with energy levels of $0.16,0.25,0.57$, 0.78 , and $1.1 \mathrm{eV}$. We have compared our results with those reported in the literature and, consequently, we succeeded in attributing either an acceptor or a donor character to a few of these levels. Moreover, in some cases, we could also assign them an origin. Dark current vs temperature measurements confirmed the key role played by the $0.78-\mathrm{eV}$ deep level in controlling the electrical properties of this material.

This research has been partially supported by the Cooperation Programme "Azione Integrata" between Italy and Spain and by DGICYT (Project No. PB93-1256). The authors are indebted to Professor F. Casali for providing the samples.
${ }^{1}$ C. Barnett Davis, D. D. Allred, A. Reyes-Mena, J. GonzalezHernandez, O. Gonzales, B. C. Hess, and W. P. Allred, Phys. Rev. B 47, 13363 (1993).

${ }^{2}$ P. Blood and J. W. Orton, The Electrical Characterization of Semiconductors: Majority Carriers and Electron States (Academic, London, 1992), Chap. 9, pp. 478-497.

${ }^{3}$ C. Hurtes, M. Boulou, M. Mitonneau, and D. Bois, Appl. Phys. Lett. 32, 821 (1978).

${ }^{4}$ Z. Fang, L. Shan, T. E. Schlesinger, and A. G. Milnes, Solid State Electron. 32, 405 (1989).

${ }^{5}$ S. Fuyuki, N. Hyakutake, and S. Hayakawa, Jpn. J. Appl. Phys. 17, 851 (1978).

${ }^{6}$ K. Suzuki, K. Inagaki, N. Kumura, I. Tsubono, T. Sawada, K. Imai, and S. Seto, Phys. Status Solidi A 147, 203 (1995).

${ }^{7}$ Y. P. Varshni, Physica 34, 149 (1967).

${ }^{8}$ E. Lopez-Cruz, J. Gonzalez-Hernandez, D. D. Allred, and W. P. Allred, J. Vac. Sci. Technol. A 8, 1934 (1990).

${ }^{9}$ D. M. Hofmann, W. Stadler, K. Oettinger, B. K. Meyer, P. Omling, M. Salk, K. W. Benz, E. Weigel, and G. Müller-Vogt, Mater. Sci. Eng. B 16, 128 (1993).

${ }^{10}$ M. Fiederle, D. Ebling, C. Eiche, D. M. Hofmann, M. Salk, W. Stadler, K. W. Benz, and B. K. Meyer, J. Cryst. Growth 138, 529 (1994).

${ }^{11}$ C. Eiche, D. Maier, D. Sinerius, J. Weese, K. W. Benz, and J. Honerkamp, J. Appl. Phys. 74, 6667 (1993).

${ }^{12}$ D. M. Hofmann, D. Omling, H. G. Grimmeiss, B. K. Meyer, K. W. Benz, and D. Sinerius, Phys. Rev. B 45, 6247 (1992).
${ }^{13}$ J. P. Zielinger, M. Tapiero, Z. Guellil, G. Roosen, P. Delaye, J. C. Launay, and W. Mazoyer, Mater. Sci. Eng. B 16, 273 (1993).

${ }^{14}$ M. Hage-Ali and P. Siffert, Nucl. Instrum. Methods Phys. Res. Sect. A 322, 313 (1992).

${ }^{15}$ W. Stadler, D. M. Hoffman, H. C. Alt, T. Muschik, B. K. Meyer, E. Weigel, G. Müller-Vogt, M. Salk, E. Rupp, and K. W. Benz, Phys. Rev. B 51, 10619 (1995).

${ }^{16}$ J. W. Allen, Semicond. Sci. Technol. 10, 1049 (1995).

${ }^{17}$ A. Castaldini, A. Cavallini, B. Fraboni, L. Polenta, and J. Piqueras (unpublished).

${ }^{18}$ T. L. Larsen, C. F. Varotto, and D. A. Stevenson, J. Appl. Phys. 43, 172 (1972).

${ }^{19}$ F. Schmidlin and G. Roberts, Phys. Rev. Lett. 20, 1173 (1968).

${ }^{20}$ U. Pal, J. Piqueras, P. Fernandez, M. D. Serrano, and E. Dieguez, J. Appl. Phys. 76, 3720 (1994).

${ }^{21}$ U. Pal, P. Fernandez, J. Piqueras, N. V. Suchinski, and E. Dieguez, J. Appl. Phys. 78, 1992 (1995).

${ }^{22}$ H.-X. Han, B. J. Feldman, M. L. Wroge, D. J. Leopold, and J. M. Ballingall, J. Appl. Phys. 61, 2670 (1987).

${ }^{23}$ P. Moravec, M. Hage-Ali, L. Chibani, and P. Siffert, Mater. Sci. Eng. B 16, 223 (1993).

${ }^{24}$ P. Höschl, P. Moravec, J. Franc, E. Belas, and R. Grill, Nucl. Instrum. Methods Phys. Res. Sect. A 322, 371 (1992).

${ }^{25}$ N. V. Agrinskaya and E. N. Arkadeva, Nucl. Instrum. Methods Phys. Rev. Sect. A 283, 260 (1989).

${ }^{26}$ T. Takebe, J. Saraie, and H. Matsunami, J. Appl. Phys. 53, 457 (1982). 